\title{
A gente faz história: tecnologias digitais e trocas culturais entre alunos brasileiros e americanos em uma escola UCA
}

\author{
Lavina Lúcia Vieira Lima ${ }^{1}$, Rita de Fátima Muniz ${ }^{2}$, Demetrius Abreu de Lima ${ }^{1}$, \\ Dennys Leite Maia ${ }^{3}$, Mixilene Sales Santos Lima ${ }^{1}$, Jaiane Ramos Barbosa ${ }^{1}$, \\ Alisandra Cavalcante Fernandes ${ }^{1}$, José Aires de Castro Filho ${ }^{1}$. \\ ${ }^{1}$ Instituto UFC Virtual - Universidade Federal do Ceará (UFC). Caixa Postal: 60440- \\ 554 - Fortaleza - CE - Brasil \\ ${ }^{2}$ EMEF LI Senador Carlos Jereissati. Jijoca de Jericoacoara - CE - Brasil \\ ${ }^{3}$ Programa de Pós-Gaduação em Educação Brasileira da Universidade Federal do \\ Ceará. Fortaleza - CE - Brasil \\ \{lavina, mixilene, jaiane, alisandra, freire, aires\}@virtual.ufc.br; \\ ritamunizjijoca@gmail.com; dennysleite@hotmail.com
}

\begin{abstract}
Cultural diversity has been a theme highlighted in the news due to contact, direct or indirect, provided by digital technologies of information and communication (TDIC). In this sense, the school is a space where learning about other cultures can be systematized, promoting respect between people of different places. One of the potential of educational laptops Project UCA is the possibility of using them as tools to promote the implementation of various activities. In this paper we present a project about culture developed in a school UCA in order to understand how the activities were regarded by the participants of the same. We conclude that different learning has been implemented and the project UCA laptop and its tools were essential to their learning.
\end{abstract}

Resumo. A diversidade cultural tem sido tema em destaque na atualidade, devido ao contato, direto ou indireto, proporcionado pelas tecnologias digitais de informação e comunicação (TDIC). Nesse sentido, a escola é espaço em que a aprendizagem sobre outras culturas pode ser sistematiza, promovendo o respeito entre pessoas de lugares diferentes. Um dos potenciais dos laptops educacionais do Projeto UCA é a possibilidade de utilizá-los como ferramentas que favoreçam a realização de diversas atividades. Nesse artigo, apresentamos um projeto sobre diversidade cultural desenvolvido em uma escola UCA a fim de perceber como as atividades foram encaradas pelos participantes do mesmo. Concluímos que diferentes aprendizagens foram realizadas e que o laptop do projeto UCA e suas ferramentas foram essenciais para as aprendizagens.

\section{Introdução}

A diversidade cultural tem sido tema em destaque na atualidade, devido ao contato, direto ou indireto, proporcionado pelas tecnologias digitais de informação e comunicação (TDIC) entre pessoas de lugares diferentes. Esse contato se dá em diversos momentos do cotidiano, através de diferentes ferramentas: assistindo a um filme, nas redes sociais, ou mesmo conversando com pessoas em bate-papos online. 
Assim, a escola, como espaço de aprendizagem não apenas de conteúdos formais, mas também de convivência em sociedade, se torna ambiente propício para $\mathrm{o}$ desenvolvimento de atividades que possibilitem o trabalho com a diversidade, de forma a preparar os alunos para a vida em uma sociedade cada vez mais globalizada, porém, sem que se percam as suas raízes culturais.

Esse artigo apresenta as atividades (e seus resultados, na visão dos participantes) do projeto "A gente faz história", realizado em uma escola do município de Jijoca de Jericoacoara - Ceará, durante o mês de Junho de 2012. O referido projeto teve como objetivo principal o contato presencial entre os alunos das turmas de $9^{\circ}$ ano da escola e sete alunos americanos de intercâmbio, visando as trocas culturais entre os participantes. Nossa análise consiste em um relato de experiência e terá cunho qualitativo/interpretativo a medida que utilizará como dados diários de campo (registros de observações dos encontros), comentários em um fórum no ambiente Sócrates e questionários semiestruturados com alguns participantes.

A seguir, serão apresentadas algumas ideias sobre Cultura, Educação e Tecnologia, bem como a relação entre esses conceitos, de forma a basear a nossa análise. Em seguida, o projeto em questão será detalhado, justificando a sua realização e explicando as suas etapas de desenvolvimento. Logo após, os resultados desse estudo e nossas conclusões sobre ele serão apresentados. Por fim, temos as referências bibliográficas utilizadas.

\section{Educação e Diversidade Cultural}

Nesta seção, faremos uma discussão teórica acerca dos temas relevantes ao artigo, de forma a basear nossa análise ao longo desse texto.

\subsection{Cultura e Diversidade Cultural}

A cultura, como é encarada no cotidiano, diz respeito a um conceito tradicional, cujo significado está relacionado à erudição de alguém: dizemos que uma pessoa é "culta", quando esta se destaca em assuntos acadêmicos, ou que a pessoa "tem cultura" quando demonstra conhecimento em relação a outros lugares do mundo, por exemplo. Porém, hoje, entendemos que cultura é algo mais amplo, que abrange todos os indivíduos de determinada sociedade e/ou comunidade e as relações que estabelecem entre si e com o meio. Segundo Geertz, a cultura é "um sistema de concepções herdadas expressas em formas simbólicas por meio das quais os homens comunicam, perpetuam e desenvolvem seu conhecimento e suas atividades em relação a vida" (1989:103).

A abordagem dos diferentes tipos de cultura dentro do contexto escolar torna-se fundamental no Brasil, onde a miscigenação é traço característico da população. De acordo com o $10^{\circ}$ volume dos Parâmetros Curriculares Nacionais (PCN) - Pluralidade Cultural, "o Brasil tem produzido também experiências de convívio e de interetnicidade, a reelaboração das culturas de origem, constituindo algo intangível que se tem chamado de brasilidade" [Brasil 1997:20]. Nesse sentido, as relações sociais funcionam como ferramentas que educam e formam indivíduos mais conscientes da sua própria realidade [Dayrell 1996].

\subsection{Educação e Interculturalidade}

A escola é, em sua origem, espaço de encontro entre experiências, costumes e hábitos diversos, ou seja, encontro entre culturas individuais dos alunos, mas ao mesmo tempo, espaço de reprodução da cultura aceita como geral (da comunidade ou sociedade). Nela, 
os alunos devem aprender não apenas conteúdos formais - conhecimentos considerados importantes a vivencia - mas também acerca de hábitos e costumes considerados adequados ao convívio em sociedade.

Entretanto, as experiências trazidas pelos alunos tendem a ser diversas, devido aos grupos culturais em que estão inseridos fora da escola (como a religião e a família, por exemplo). A interculturalidade é entendida como a relação ou interação entre culturas diferentes de forma horizontal, ou seja, sem que nenhuma cultura seja inferior ou superior às outras. Dessa forma, o respeito à diversidade é construído.

Entendendo que na diversidade é possível a construção de um diálogo entre as culturas individuais dos alunos com eles mesmos e com as culturas locais, Cortesão e Stoer (1996) propõem a valorização das culturas locais e a garantia da comunicação entre as culturas como estratégias pedagógicas para a construção da interculturalidade pelos alunos.

Com base nessa compreensão, o projeto aqui analisado foi planejado e elaborado, obejetivando a construção de conhecimentos sobre as culturas participantes pelos alunos, mas também a valorização das suas próprias. Ao longo do nosso texto, pretendemos verificar se esse objetivo foi realmente alcançado.

\section{O Projeto UCA}

Para contextualizar o ambiente em que o projeto ocorreu, nos pareceu necessário apresentar o projeto UCA na referida escola.

\subsection{O que é o programa Um Computador por Aluno e como funciona}

O Projeto Um Computador por Aluno (UCA) foi iniciado em 2007 pelo governo brasileiro em uma fase pré-piloto. Na ocasião, cinco escolas públicas brasileiras foram contempladas com laptops educacionais, de custo reduzido. Após essa etapa de experimentos, no ano de 2010, foi dado início à fase 2 do projeto-piloto, com a participação de aproximadamente 300 escolas públicas do país, distribuídas nas 27 unidades da federação. Em todo o país, foram distribuídos 150.000 computadores para as escolas selecionadas. O estado do Ceará foi beneficiado com a participação de 9 escolas: 2 situadas na capital e as demais no interior do estado, dentre as quais está a que serviu de lócus para este estudo. Com essas experiências iniciou-se, oficialmente, no Brasil o modelo de informática educativa na situação um para um (1:1), que prevê um computador para cada estudante [Valente 2011].

Nesse novo paradigma, os computadores fixos (desktops) são substituídos por dispositivos móveis (laptops, tablets, smartphones, etc), com conexão à internet, para serem utilizadas em práticas educativas. Dessa maneira, o uso do computador deixa de ser um momento pontual, por vezes, raro, nos laboratórios de informática e previamente planejados, para tornar-se uma prática corrente de sala de aula, nos diversos espaços da escola e fora dela.

No modelo 1:1 as vantagens para o processo de ensino e aprendizagem podem ser vislumbradas a partir do momento que os sujeitos passem a utilizar os equipamentos visando a aquisição de informações e a construção de conhecimentos. Para tanto é necessário que professores e alunos percebam que tais equipamentos podem "ampliar seu acesso à informação, desenvolver habilidades de produção, adquirir novos saberes, expandir a sua inteligência e participar da construção coletiva do conhecimento" [Brasil 2007:12]. 
No caso dos laptops educacionais do Projeto UCA, um dos potenciais desses equipamentos é a possibilidade de utilizá-los como ferramentas que favoreçam a interação entre professores e alunos, alunos e alunos e professores e professores e esses com o mundo. Neste sentido, a proposta deste texto é analisar as trocas culturais entre alunos e professores de uma escola no interior do estado do Ceará, com estudantes americanos. A seguir, o referido projeto será melhor detalhado.

\subsection{O Projeto UCA na EMEF LI Senador Carlos Jereissati}

O Projeto UCA foi implantado na Escola Senador Carlos Jereissati no ano de 2010, contemplando todos os gestores, professores e alunos. Desde então, os professores têm participado de formações para o uso do laptop educacional em sala de aula e são acompanhados periodicamente por uma equipe da Universidade Federal do Ceará UFC, que os orienta e apoia em suas ações com o uso dos computadores.

A partir da chegada dos laptops, e com as formações pelas quais participaram das formações, os profissionais da escola, em especial, os professores, independente da disciplina que lecionam, têm tentado planejar suas aulas conciliando os conteúdos com as opções de ferramentas digitais (como os blogs e objetos de aprendizagem, por exemplo) e ao mundo de informação a que se pode ter acesso através da internet. Um dos exemplos dessas atividades planejadas com o auxílio do laptop educacional foi o projeto de intercâmbio cultural detalhado a seguir.

\section{O projeto A gente faz história}

O projeto A gente faz história foi elaborado por uma equipe do Instituto UFC Virtual conjuntamente com a gestão e professores da escola em conversas por e-mail, quando a gestão demonstrou interesse em participar do mesmo. Após esse primeiro contato, foi feita uma reunião com a gestão da escola em que se definiu o período e os temas a serem abordados no projeto, em consonância com conteúdos que já estavam definidos para serem trabalhados pela escola durante o mês de junho. Em seguida, foi apresentada a proposta aos professores e a professora de Inglês e Português das turmas de $9^{\circ}$ ano da escola se disponibilizou a participar do projeto. Dessa forma, foi criado um projeto no ambiente Sócrates, através do qual os participantes poderiam se conhecer antes do contato presencial, que se faria dali a um mês ${ }^{1}$.

\subsection{Participantes}

Participaram do projeto as quatro turmas do $9^{\circ}$ ano existentes na escola (turnos manhã e tarde), totalizando 119 alunos e 2 professores, a professora de Línguas Portuguesa e Estrangeira (Inglês) e o professor de Informática das referidas turmas. Além deles, sete alunos americanos que estavam em um intercâmbio na UFC também tiveram participação no projeto, sendo essa uma das atividades obrigatórias durante a sua estadia. Estes alunos eram advindos de cursos de graduação e pós-graduação de duas universidades americanas e tinham idades entre 19 e 32 anos. Quatro deles representavam a USU - Utah State University (Universidade do Estado de Utah) e os outros três, a UGA - University of Georgia (Universidade da Geórgia). Por fim, seis

\footnotetext{
${ }^{1} \mathrm{O}$ projeto foi pensado para acontecer em uma semana (iniciando na segunda-feira e se encerrando na sexta-feira) devido à distância entre a capital e a cidade de Jijoca de Jericoacoara, para onde os participantes americanos e estudantes da UFC envolvidos na organização deveriam ir durante a execução das atividades presenciais do projeto.
} 
alunos de graduação e pós-graduação da UFC formaram com a gestão da escola (diretor e coordenadora pedagógica) a equipe de organização do projeto.

Em relação ao idioma, os intercambistas já estavam familiarizados com o Português, pois haviam frequentado cursos antes de chegarem ao Brasil e continuaram a ter aulas de Língua Portuguesa para estrangeiros durante o tempo em que ficaram no país. Dessa forma, o idioma utilizado em todas as atividades era o Português. A equipe de organização ajudava, ambos os lados, sempre que necessário, a traduzir o que se tinha dificuldade de entender.

\subsection{Atividades desenvolvidas}

A gestão da escola (diretor e coordenadora pedagógica), juntamente com seis alunos de graduação e pós-graduação da universidade foram responsáveis pela organização das atividades do projeto, as quais foram planejadas com os professores participantes, em especial, com a professora de Língua Portuguesa e Inglesa.

A temática abordada - trocas culturais - foi explorada nas aulas de Português através do estudo de personalidades da cultura de cada estado - Ceará, no Brasil, e Georgia, Utah e Massachussets, neios Estados Unidos da América (EUA), estados dos estudantes americanos. Assim, o objetivo do referido projeto era que ambos os alunos (americanos e brasileiros) construíssem conhecimento acerca da cultura dos colegas. No direcionamento do trabalho, foram escolhidos quatro temas: Literatura, Humor, Música e História. Cada turma de $9^{\circ}$ ano ficou responsável por desenvolver um dos temas. Em todas as turmas, foram formados seis grupos e para cada um dos temas foram eleitas seis personalidades que melhor representassem tais aspectos. Assim, as turmas fariam seis apresentações durante a aula.

No período anterior ao início dos encontros presenciais (cerca de duas semanas), foram realizadas aulas no laboratório de informática para os alunos pesquisarem na web sobre seus respectivos temas e personagens durante as aulas de Língua Portuguesa. Além disso, também no laboratório, os alunos utilizavam o fórum do ambiente Sócrates para debater uns com os outros e com os demais envolvidos no projeto acerca de suas expectativas e anseios sobre o contato com os estudantes de outro país, aproveitando para dividirem experiências e trocarem informações sobre os temas abordados.

$\mathrm{Na}$ semana em que os encontros presenciais aconteceram, foram realizadas duas aulas com cada turma, durante três dias (Tabela 1). Como os encontros aconteciam durante os horários das aulas de Português e Inglês, as atividades ficaram dependentes desses horários. Além dos encontros durante as aulas, foi formado um grupo de seis alunos, representantes de todas as turmas, para participarem de uma entrevista mútua, que foi uma espécie de bate-papo entre eles e os estudantes americanos, na qual o principal tema seria as curiosidades dos participantes sobre a cultura dos colegas.

Nos primeiros encontros, realizados logo no primeiro dia, foi explicado pela equipe do projeto, juntamente com a professora de sala de aula, as atividades que seriam feitas durante a semana. Logo depois dessa explicação, pediu-se que os alunos da escola se apresentassem, dizendo seu nome e idade. Em seguida, os estudantes americanos fizeram suas apresentações. Eram três apresentações (uma para cada estado representado) e os estudantes utilizavam diferentes mídias e atividades.

Tabela 1: Encontros, atividades e temas desenvolvidos.

\begin{tabular}{|l|l|l} 
Encontro & $\begin{array}{l}\text { Quantidade de } \\
\text { aulas }\end{array}$ & Atividade e temas desenvolvidos \\
\hline
\end{tabular}




\begin{tabular}{|c|c|c|c|}
\hline \multirow{4}{*}{$1^{\circ}$ dia } & $9^{\circ} \mathrm{A}$ (manhã) & \multirow{4}{*}{$\begin{array}{l}\text { Apresentações dos } \\
\text { estudantes americanos } \\
\text { sobre seus estados. }\end{array}$} & \multirow{4}{*}{$\begin{array}{l}\text { Utah } \\
\text { Georgia } \\
\text { Massachussets }\end{array}$} \\
\hline & $9^{\circ} \mathrm{B}$ (manhã) & & \\
\hline & $9^{\circ} \mathrm{C}$ (manhã) & & \\
\hline & $9^{\circ} \mathrm{D}$ (manhã) & & \\
\hline \multirow{6}{*}{$2^{\circ} \mathrm{dia}$} & \multirow{6}{*}{$9^{\circ} \mathrm{B}$ (manhã) } & \multirow{6}{*}{$\begin{array}{l}\text { Apresentações da turma } \\
\text { sobre Literatura }\end{array}$} & Manuel Bandeira \\
\hline & & & José de Alencar \\
\hline & & & Ariano Suassuna \\
\hline & & & Patativa do Assaré \\
\hline & & & Jorge Amado \\
\hline & & & Raquel de Queiroz \\
\hline \multirow{17}{*}{$3^{\circ}$ dia } & \multirow{6}{*}{$9^{\circ} \mathrm{A}$} & \multirow{6}{*}{$\begin{array}{l}\text { Apresentações da turma } \\
\text { sobre Humor }\end{array}$} & Renato Aragão \\
\hline & & & Tom Cavalcante \\
\hline & & & Chico Anysio \\
\hline & & & Shaolin \\
\hline & & & Tiririca \\
\hline & & & Zé Lezim \\
\hline & \multirow{5}{*}{$9^{\circ} \mathrm{D}$} & \multirow{5}{*}{$\begin{array}{l}\text { Apresentações da turma } \\
\text { sobre Música }\end{array}$} & Fagner \\
\hline & & & Falcão \\
\hline & & & Luiz Gonzaga \\
\hline & & & Zé Ramalho \\
\hline & & & Elba Ramalho \\
\hline & \multirow{6}{*}{$9^{\circ} \mathrm{C}$} & \multirow{6}{*}{$\begin{array}{l}\text { Apresentações da turma } \\
\text { sobre História }\end{array}$} & Lula (ex-presidente) \\
\hline & & & Edson Queiroz \\
\hline & & & Paulo Freire \\
\hline & & & Lampião \\
\hline & & & Maria da Penha \\
\hline & & & Padre Cícero \\
\hline $4^{\circ}$ dia & \multicolumn{3}{|c|}{ Conversa sobre curiosidades } \\
\hline $5^{\circ}$ dia & \multicolumn{3}{|c|}{ Encerramento - Festa Junina } \\
\hline
\end{tabular}

Nas apresentações sobre Utah, os quatro estudantes da USU fizeram uma apresentação de slides, bem como dinâmicas com os alunos brasileiros, nas quais eles ensinavam um pouco de inglês através de uma brincadeira que envolvia a dança, além de apresentar outras brincadeiras típicas do estado. Além disso, a filha de uma das estudantes cantou algumas músicas infantis típicas da cidade. As apresentações sobre a Georgia, feitas por duas alunas da UGA, focaram em personalidades da capital, Atlanta, e utilizaram videoclips musicais, além de apresentação de slides com fotos e textos. Uma das alunas também chamou um aluno, de forma voluntária, para ensiná-lo uma dança típica do seu estado. Por fim, a apresentação sobre Massachussets, estado natal da terceira aluna da UGA, procurou evidenciar as diferenças e semelhanças, através de alguns aspectos, entre a cultura de onde ela nasceu e a brasileira/cearense, percebidas por ela, que estava há cerca de um mês em Fortaleza.

Ao final de cada apresentação, perguntava-se se havia alguma dúvida em relação ao que havia sido apresentado, mas em geral, os alunos brasileiros diziam não haver dúvidas ou questionamentos. Entendemos que isso se deu devido à timidez dos alunos em perguntar algo na frente dos colegas e da professora, e até mesmo pela novidade que 
eram os encontros, já que a maioria nunca tinha tido a oportunidade de um contato tão próximo com pessoas de outros países.

Nos encontros seguintes, os alunos da escola fizeram as suas apresentações, em grupos, por meio de explicações, fotos, textos e vídeos, nos quais mostravam documentários e entrevistas com as personalidades apresentadas, bem como livros e painéis. Uma das equipes também apresentou uma coreografia para ilustrar uma dança típica da região e a obra do artista pelo qual ficou responsável. Outra equipe ainda recitou um poema que foi escrito pela personalidade que estava apresentando. Ao final de cada apresentação, também eram feitos questionamentos por parte dos estudantes norte-americanos a respeito do que cada equipe abordou. Segundo a professora de sala, "neste momento, ocorria uma excelente troca de informações e conhecimentos entre os brasileiros e americanos". Durante todas as apresentações, os estudantes intercambistas demonstraram bastante interesse no que estava sendo mostrado pelos alunos da escola, fazendo várias anotações pessoais.

Para a atividade da entrevista mútua, a professora de sala debateu em cada turma algumas curiosidades dos alunos em relação à cultura americana e escolheu os alunos que iriam participar do debate. Os alunos elaboraram as perguntas de acordo com o que foi proposto dentro de sala, tanto por eles mesmos quanto pelos outros colegas da turma e também se prepararam para responder os questionamentos. Os estudantes norteamericanos também elaboraram perguntas previamente para serem feitas aos estudantes da escola. A realização da atividade ocorreu na biblioteca da escola e foi um momento descontraído, em que os participantes (cinco alunos da escola e cinco estudantes americanos) puderam debater sobre temas que lhes interessavam acerca da cultura dos colegas. $\mathrm{O}$ bate-papo iniciou-se tímido, sendo mediado pela equipe de organização, mas ao longo dos 40 minutos de conversa, todos se sentiram a vontade tanto para perguntar como para responderem as questões feitas de forma tranquila e livre.

Além de todas as atividades desenvolvidas dentro da sala de aula, o horário do intervalo também foi um momento muito interessante e rico de troca cultural. Os alunos da escola estavam sempre em volta dos norte-americanos e mesmo de forma discreta no início, logo, todos estavam interagindo, conversando, tirando dúvidas, fotografando.

Para estreitar mais ainda os laços, no último dia, houve um evento na escola que reuniu alunos e funcionários, além dos intercambistas e estudantes da UFC. Pela manhã, todos puderam interagir uns com os outros além de colaborar na decoração do evento, que ocorreu na quadra esportiva da escola, pela tarde.

\section{Resultados}

Ao longo do projeto, foram percebidos alguns aspectos relevantes em relação ao contato e à aprendizagem dos participantes. Nesta seção apresentamos uma breve análise acerca das percepções dos participantes (alunos norte-americanos, brasileiros e professores envolvidos) acerca do projeto, a fim de entender de que forma as experiências vivenciadas puderam contribuir para uma aprendizagem sobre a diferença e como os materiais desenvolvidos para o projeto e durante ele podem representar esse contato. Para tanto, utilizaremos depoimentos da professora de sala de aula, dos participantes, bem como as observações feitas durante as atividades, em especial, durante aquela que chamamos entrevista mútua.

\subsection{Expectativas para o projeto}


Quando o projeto foi apresentado aos alunos das turmas de $9^{\circ}$ ano, aproximadamente duas semanas antes dos encontros presenciais, todos adoraram a ideia de participarem de um intercambio cultural. Além disso, durante a preparação das apresentações (fase de pesquisa), a professora de sala relata que os alunos se mostraram empolgados, pois disseram perceber a chance de conhecer pessoas de outro país, trocar experiências e aprender mais sobre o seu próprio estado e sobre os estados americanos. Seguem, abaixo, alguns comentários feitos no ambiente Sócrates, sobre as expectativas dos alunos:
"Espero que esse projeto seja maravilhoso pois vai mostrar nossa cultura nordestina que é enorme e linda pois é uma mistura de gostos. Tomara que todos gostem". (aluno A)
"Deve ser bastante interessante, descobrir um pouco mais de outros lugares, conhecer pessoas novas e aprender mais sobre mais culturas que se diferenciam da nossa". (aluna B)
"Eu acho que esse projeto vai ser muito legal e vai nós ajudar muito e assim vai dar para a gente conhecer as culturas que tem por ai a fora e também conhecer pessoas novas"..(aluno C)

Nos comentários acima, percebemos o interesse não apenas em conhecer a cultura dos outros, mas também em poder apresentar aspectos da sua cultura. A aprendizagem, assim, se dá de forma mútua: os alunos tanto podem aprofundar seu conhecimento sobre o assunto como também ensinar outras pessoas. Entendemos que esse interesse em relação às atividades que seriam realizadas pode facilitar a aprendizagem dos conteúdos estudados, com as experiências vivenciadas.

\subsection{Participação nas atividades e aprendizagens desenvolvidas}

Durante a realização das atividades do projeto, em especial, nas apresentações feitas pelos alunos brasileiros, a professora de sala disse ter se surpreendido, pois, segundo ela, "alunos tímidos tiveram coragem de apresentar seus trabalhos e outros alunos desinteressados, estudaram bastante para fazer bem feito". Dessa forma, pudemos entender que o projeto em si, teve papel importante na motivação para realizar as atividades.

5.2.1. O uso de ferramentas digitais para as apresentações e as aprendizagens desenvolvidas

Algumas equipes de alunos utilizaram, em suas apresentações, não apenas slides, mas vídeos, com o conteúdo em forma de fotos, vídeos e textos, para ilustrarem o tema que abordavam. Segundo o professor do laboratório, alguns deles aprenderam a usar um editor de vídeo no próprio laptop educacional para elaborar os materiais. Dessa forma, também houve aprendizagem quanto à familiarização com a tecnologia, utilizando-a não de forma isolada, mas como ferramenta para produção e apresentação de trabalhos, pois os alunos desenvolveram formas criativas de fazê-lo para que as mesmas ficassem interessantes.

Para a professora de sala, "foi gratificante ver meus alunos empolgados e empenhados em desenvolver um trabalho de qualidade. Todos acolheram esta ideia e a utilizaram em sua rotina escolar". Quando a professora menciona a rotina, ela que quer dizer que os alunos se envolveram bastante nas atividades e, como tinham liberdade de utilizar os laptops sempre que precisassem, o fizeram de forma ativa, para criar os materiais para os encontros presenciais, bem como para participar do fórum criado no ambiente interativo.

\subsection{2. "Entrevista mútua"}


A entrevista mútua começou com uma dinâmica em que os americanos e os brasileiros fizeram as perguntas de forma alternada. No início parecia haver um clima de nervosismo de ambas as partes, mas aos poucos, a dinâmica foi se tornando um batepapo descontraído e natural, no qual a mediação se tornou quase desnecessária. Por conta do conforto que foi sendo adquirido pelos participantes, além das perguntas que já tinham sido elaboradas anteriormente, surgiram novas dúvidas e curiosidades.

A conversa se baseou nas impressões iniciais que cada grupo tinha sobre a cultura do outro, além das impressões individuais. Segundo os alunos da escola, a maior curiosidade era sobre o que os estudantes de intercâmbio estavam achando da cidade e de tudo o que já havia sido apresentado a eles. Notava-se também que os brasileiros recebiam os elogios dos colegas americanos com muita alegria, fazendo seu orgulho pelo local onde viviam ser cada vez mais perceptível, quando concordavam com o elogio ou acrescentavam alguma informação a ele. Por sua vez, o grupo de estudantes de intercambio quis saber que local nos Estados Unidos os alunos brasileiros gostariam de conhecer.

Os alunos da escola ainda tiveram interesse em saber sobre as dificuldades dos americanos com a Língua Portuguesa e as suas profissões (já que os alunos de intercambio já estavam na universidade). Os americanos falaram sobre o que eles estudavam/trabalhavam e os brasileiros, que profissão eles gostariam de seguir futuramente.

\subsection{Impressões sobre o projeto}

A escola, de forma geral, esteve bastante envolvida no desenvolvimento do projeto, já que procurou envolver todos os participantes também em outras atividades que estavam sendo realizadas, como a organização e decoração da festa junina que se realizaria no último dia do projeto. Tanto o corpo docente como os alunos de outras turmas valorizaram o fato da escola participar de um projeto assim e ainda procuraram aproveitar essa oportunidade, "conversando" com os estudantes do intercâmbio sobre curiosidades suas, durante os intervalos das aulas. Essas interações entre os participantes aconteciam de forma livre e natural, envolvendo temas de seu interesse e curiosidade, mesmo com a dificuldade do idioma (já que alguns estudantes americanos não dominavam totalmente a língua portuguesa).

Segundo alguns estudantes americanos, as apresentações dos alunos brasileiros foram muito interessantes e ricas. Para eles, foi muito importante aprender sobre a história do estado. Também relatam que as apresentações em si (mídias e materiais apresentados) foram criativas e os ajudaram a entender os assuntos abordados. Durante as apresentações, os estudantes fizeram perguntas sobre as obras literárias e sobre o trechos de filmes apresentados, e disseram ter vontade de ler os livros e assistir aos filmes citados nos slides, por exemplo.

No entanto, de acordo com a gestão, professores e alunos brasileiros, quando questionados sobre o que poderia ter sido melhor no projeto, disseram que se os estudantes americanos tivessem a mesma faixa etária que eles (entre 14 e 16 anos), a troca cultural teria sido ainda mais interessante, uma vez que, segundo eles, haveria mais motivação para aprender sobre e com os colegas. Além disso, o estudo da língua inglesa poderia ter sido mais trabalhado, em atividades presenciais com esse objetivo ou em fóruns no ambiente virtual. Isso mostra, a nosso ver, que alunos e professora da escola em questão já percebem o uso de espaços virtuais como ambiente possível de trocas e aprendizagens. 
Além disso, alguns estudantes americanos disseram que gostariam de ter tido mais tempo na escola e no projeto, principalmente para terem atividades mais interativas, "como foi a entrevista mútua" (estudantes de intercâmbio 1), a qual, segundo eles, foi a atividade que mais gostaram. Contudo, todos concordam que houve grandes aprendizagens resultantes do Projeto, para todos os participantes.

\section{Conclusões}

A entrada das TDIC na escola tem sido encarada como um desafio para professores e equipe gestora, visto que é uma ferramenta a mais para ser utilizada no cotidiano educacional e costuma modificar toda a rotina escolar. Entretanto, entendemos que, se utilizada em contextos apropriados, as ferramentas digitais tem potencial para auxiliar professores e contribuir para a aprendizagem dos alunos.

No projeto aqui apresentado, podemos perceber que, embora as tecnologias não sejam o centro do trabalho desenvolvido, elas foram essenciais para o bom andamento das atividades, utilizadas como suporte à elaboração de materiais de apresentação de conteúdo e de comunicação entre os participantes. Além disso, como os alunos da escola já estavam habituados à utilização do laptop em suas atividades cotidianas, não foi necessário pedir a eles que utilizassem em todas as atividades, mas eles o fizeram.

Assim, podemos concluir que as TIDC (no caso, através do projeto UCA) contribuem para o desenvolvimento de diferentes atividades, entendendo que, tornandose parte da rotina dos alunos, o desenvolvimento de trabalhos envolvendo conteúdos diversos, o laptop passa a ser natural na elaboração de diferentes materiais por parte deles.

\section{Referências bibliográficas}

BRASIL. "Princípios orientadores para o uso pedagógico do laptop na educação escolar". Brasília: 2007.

CORTESÃO, L.; STOER, S. “A Interculturalidade e a Educação Escolar: Dispositivos Pedagógicos e a Construção da Ponte Entre Culturas”. Inovação, Volume 9, nº 1 e 2. Lisboa: Instituto de Inovação Educacional, 1992.

DAYRELL, Juarez Múltiplos olhares sobre educação e cultura. Belo Horizonte: Ed. UFMG, 1996.

GEERTZ, C. “A interpretação das culturas”. Rio de Janeiro: LTC, 1989.

VALENTE, J. A. "Um laptop para cada aluno: promessas e resultados". In: ALMEIDA, M. E. B. de; VALENTE, J. A. O computador portátil na escola: mudanças e desafios nos processos de aprendizagem, São Paulo, Avercamp, 2011. 